\title{
O PÊNDULO BRASILEIRO: ATÉ QUANDO?
}

Danilo Enrico Martuscelli*

O processo de desenvolvimento capitalista na América Latina tem sido marcado por sucessivas crises de acumulação de capital e de dominação política, o que tem ocasionado bruscas e frequentes mudanças no conteúdo da política econômica e social e nas relações de classe.

Em meados dos 1970, o economista Marcelo Diamand fez uso da metáfora do pêndulo para explicar as oscilações recorrentes da política econômica argentina que, em grande medida, derivariam das disputas entre duas "correntes antagônicas" do pensamento econômico: a corrente populista (mais tarde chamada por ele de "corrente expansionista ou popular") e a corrente ortodoxa econômica (posteriormente denominada por ele como "liberalismo econômico"). ${ }^{1}$

A primeira refletiria os anseios das massas populares, já que teria considerável impactoredistributivo e na criação de emprego, estaria mais conectada com a ideia de soberania econômica do país, produziria relativo crescimento da atividade econômica, satisfazendo, com isso, os interesses do setor comercial e industrial, piorando a situação do agro e adotando certa política discriminatória em relação ao capital estrangeiro. A segunda corrente representaria o setor agropecuário, o setor financeiro, o exportador tradicional e, inclusive, o industrial.

Para ele, nenhuma das duas correntes seria capaz de colocar o pêndulo no meio. Ambas estariam condenadas ao fracasso econômico. A corrente populista por engendrar a desordem, o desabastecimento, a inflação e a interrupção do pagamento externo; a corrente liberal por fomentar a redução dos salários, a recessão e o endividamento externo. Ademais, tal disputa tenderia a se reproduzir em países com condição similar àArgentina - isto é, diríamos: em países dependentes com certo nível de desenvolvimento capitalista.

\footnotetext{
* Professor de Ciência Política da Universidade Federal da Fronteira Sul (UFFS), editor do blog marxismo21 e autor do livro: Crises politicas e capitalismo neoliberal no Brasil. Curitiba, CRV, 2015.

${ }^{1}$ As reflexões produzidas por Marcelo Diamand podem ser encontradas em dois artigos que possuem pequenas diferenças no conteúdo da redação: "El péndulo argentino: empate político o fracasos económicos” In: Carlos A. Floria e Marcelo Montserrat (orgs.). Pensar la República. Buenos Aires, Fundación Piñero Pacheco, 1977; e "El péndulo argentino: ¿hasta cuándo?.Cuadernos del Centro de Estudios de la Realidad Económica, Buenos Aires, n. $1,1985$.
} 
Foi o cientista político Guillermo O’Donnell quem procurou traduzir mais claramente a metáfora do pêndulo em termos conflito de classes. No artigo "Estado y alianzas en Argentina, 1956-1976”, O’Donnell observa que o movimento pendular da grande burguesia urbana em termos de aproximação (unidade) e distanciamento (contradição) em relação aos interesses da burguesia pampeana, derivaria, em grande medida, das pressões oriundas dos setores débeis da burguesia urbana em aliança com os setores populares com forte inserção operária ("aliança defensiva"). Nessa perspectiva, quando os interesses das frações superiores da burguesia entram em contradição, configura-se uma situação em que a defesa do mercado interno, o crescimento do nível de atividade econômica e a contenção da expansão do capital internacional na formação social passam a ser uma das características marcantes da "aliança defensiva". 2

Nas análises acima mencionadas, a metáfora do pêndulo é utilizada ora para examinar as disputas entre correntes do pensamento econômico (Diamand), ora para compreender os conflitos entre as frações superiores da burguesia argentina (O’Donnell). Se formos empregála à explicação da crise brasileira atual, julgamos ser preciso levar em consideração três aspectos fundamentais que têm contribuído para engendrar o movimento pendular da burguesia brasileira nas últimas décadas: 1) o papel desempenhado pelo imperialismo na formação social brasileira; 2) a relação ambivalente que a burguesia brasileira tem mantido com o imperialismo; 3) as tensões existentes entre as frações da grande burguesia e as classes dominadas nas conjunturas de crescimento significativo do protesto social. A elucidação desses três aspectos nos permite entrever a natureza da crise política atual.

\section{II}

Se nos restringirmos à análise do capitalismo neoliberal no Brasil, é possível observar três movimentos do imperialismo que estiveram profundamente conectados com a emergência das três crises políticas recentes: a crise do governo Collor (1992), a crise do "mensalão" (2005) e a crise atual (que se inicia com o processo de impeachment de Dilma Rousseff e pode ainda resultar na destituição de Michel Temer da presidência da República). ${ }^{3}$

\footnotetext{
${ }^{2}$ Ver: "Estado y alianzas en Argentina, 1956-1976". Desarrollo Económico, vol. 16, n. 64, jan-mar, 1977.

${ }^{3}$ Analisamos exaustivamente as duas primeiras crises no livro: Crises políticas e capitalismo neoliberal no Brasil. Curitiba, CRV, 2015.
} 
A crise do governo Collor está associada ao processo complexo e contraditório de transição ao neoliberalismo no Brasil. Nessa conjuntura, o imperialismo estadunidense se colocou na ofensiva política, interessado na aplicação integral do programa neoliberal pautado nas políticas de redução de direitos sociais e trabalhistas, na privatização de empresas e serviços e na abertura comercial e financeira. Este foi um processo em que o imperialismo e a burguesia a ele associada se projetaram simultaneamente como fração hegemônica do bloco no poder (hegemonia política) e como fração reinante da cena política (hegemonia ideológica). A política econômica de orientação claramente neoliberal adotada principalmente pelo governo de Fernando Henrique Cardoso e as vitórias eleitorais do PSDB nas eleições presidenciais são indicadores importantes que permitem observar o fenômeno de uma mesma fração burguesa exercendo simultaneamente a hegemonia política e ideológica nos anos 1990.

O final dos anos 1990 e início dos 2000 é uma conjuntura marcada pelo desgaste do neoliberalismo e, por conseguinte, de fortalecimento dos processos de resistências à aplicação do programa neoliberal no Brasil. Isso criou progressivamente realinhamentos políticos e ideológicos que permitiram a realização de reformas no capitalismo neoliberal. Diante dessa conjuntura, o imperialismo recuou e fez concessões que permitiram acomodar os interesses da grande burguesia interna no bloco no poder, sem com isso haver uma mudança substancial da política econômica que pudesse colocar em risco a sua hegemonia política. No entanto, no âmbito da cena política, as candidaturas mais claramente identificadas com o programa neoliberal ortodoxo foram sofrendo sucessivas derrotas nas eleições presidenciais, o que permitiu alçar a grande burguesia interna à condição de fração reinante, passando assim a exercer a hegemonia ideológica diante das classes dominadas, que obtiveram concessões materiais limitadas - mas efetivas -, especialmente quando se leva em consideração os níveis salariais, o emprego formal e a política social dos anos 1990. Nesse sentido, a crise política de 2005 expressou o início de um progressivo processo de dissociação das funções de hegemonia política e hegemonia ideológica. Entre 2005 e 2013, um dos fatos políticos mais significativos foi a emergência da grande burguesia interna como força social inclinada a realizar reformas no neoliberalismo.

A crise recente recolocou o imperialismo na ofensiva política e tem fortalecido sua presença tanto no âmbito do bloco no poder quanto na cena política. A articulação entre aparato judicial e policial e mídia corporativa com fortes mobilizações de rua contra a corrupção e contra os principais símbolos das reformas no capitalismo neoliberal (faltou concluir): a Petrobras, o BNDES, as políticas sociais e o PT (o que inclui a figura de Lula), o 
golpe de Estado perpetrado contra o governo Dilma e o conteúdo da política econômica e social do governo Temer são algumas das evidências desse processo que impede o prosseguimento da política econômica e social adotada até 2014. Diferentemente da transição ao neoliberalismo dos anos 1990, que contraditoriamente ocorreu em meio a um processo de abertura democrática e, portanto, de lutas por direitos sociais e políticos, a conjuntura atual tem sido profundamente marcada pela combinação de um neoliberalismo extremado que quer não só impor limite à soberania nacional e reduzir drasticamente os direitos sociais e trabalhistas duramente conquistados pelo povo brasileiro, como também retrocessos à frágil democracia liberal-burguesa existente no Brasil. Portanto, ao compararmos as três conjunturas, é possível observar que o imperialismo realiza três movimentos: ofensiva-recuoofensiva. Todos eles tiveram impacto sobre o conteúdo da política econômica e social e sobre as relações de classe no Brasil.

\section{III}

Como têm se comportado à grande burguesia brasileira, especialmente aqueles setores que possuem base de acumulação própria no Brasil? Aqui, é observar que se há um setor da grande burguesia brasileira que está associado ao imperialismo, agindo como uma espécie de correia de transmissão dos interesses imperialistas, não se observa nas camadas superiores da burguesia brasileira a existência de uma fração que se comportaria como uma típica burguesia nacional, interessada na ampliação do mercado interno de massas, na execução de um efetivo planejamento estatal do setor produtivo e voltada para a defesa da soberania nacional. O que existe de fato no seio das camadas superiores da burguesia brasileira é uma fração que possui uma relação ambivalente perante o imperialismo, não coincidindo nem com a posição típica de uma burguesia associada (ou compradora), nem tampouco nacional. Tratase de uma burguesia que poderíamos chamar de interna, seguindo a elaboração de Poulantzas, ${ }^{4}$ e que possui uma relação de contradição e dependência em relação ao capital estrangeiro ou ao capital imperialismo. A depender da conjuntura, a burguesia interna brasileira oscila entre um e outro polo, tornando assim mais ou menos manifestas suas contradições em relação ao imperialismo.

\footnotetext{
${ }^{4}$ Para uma análise do alcance e dos limites do conceito de burguesia interna na obra de Poulantzas, indicamos o nosso artigo: "Poulantzas e o conceito de burguesia interna". Demarcaciones, n. 2, 2014. Disponível em: https://www.academia.edu/16662235/Poulantzas e o conceito de burguesia interna
} 
Qual foi a posição adotada pela grande burguesia interna nas três conjunturas mencionadas? Na primeira, realizou resistências pontuais e seletivas ao programa neoliberal, especialmente em relação à abertura comercial desenfreada, às altas taxas de juros, às dificuldades de acesso aos subsídios e à política de câmbio sobrevalorizado. Na conjuntura do final do governo Cardoso e início do governo Lula, passou a reivindicar mais ostensivamente reformas no capitalismo neoliberal e a apoiar os governos petistas mais claramente entre 2005 e 2013. A rejeição à ALCA, os volumosos recursos do BNDES destinados às campeãs nacionais, a redução da taxa de juros, a execução de diferentes programas como: PAC (Programa de Aceleração do Crescimento), Minha casa, minha vida, PIL (Programa de Infraestrutura e Logística), a política de conteúdo nacional para as compras da Petrobras entre outras iniciativas foram fatores que contribuíram para a grande burguesia brasileira apoiar e se beneficiar nos governos petistas.

Tal posicionamento veio se alterar em meio à ofensiva imperialista. Apesar de representantes da burguesia paulista e outras tantas associações patronais terem tido forte protagonismo nas mobilizações de rua para destituir a presidente Dilma - a campanha "Não vamos pagar o pato!", encabeçada pela FIESP que exigia redução dos gastos sociais sem aumento de impostos é exemplo disto -, com o desenrolar do processo fica cada vez mais nítido que a grande burguesia interna brasileira agiu a reboque do imperialismo; seu protagonismo nas ruas foi um protagonismo subordinado aos interesses do imperialismo. As alterações promovidas pelo governo Temer na política de compras da Petrobras, reduzindo as porcentagens destinadas aos produtos nacionais, e os cortes dos recursos do BNDES são medidas que têm gerado profundo descontentamento em várias entidades patronais representativas da burguesia interna. Isso sem contar o quadro de quase recessão que dificulta mais os negócios dessa fração burguesa. Essa situação geral explica o empenho da grande burguesia interna na defesa das contrarreformas da previdência e trabalhista. Se a grande burguesia interna tem sido forte o suficiente para atacar os direitos sociais e trabalhistas para garantir a tão desejada competitividade, sua fraqueza política e ideológica é notável quando acena para algum tipo de contradição com o imperialismo. É por isso que quando o imperialismo avança, a grande burguesia interna recua, mas avança contra os trabalhadores; e quando o imperialismo recua, a grande burguesia interna avança e consegue realizar concessões materiais limitadas aos trabalhadores, mas suficientes para lograr apoio aos seus interesses. 
A história brasileira é farta de exemplos de situações nas quais à medida que o protesto social cresce vertiginosamente, isso engendra um alinhamento quase automático entre o imperialismo e a grande burguesia interna contra o movimento popular e sindical e os direitos sociais e trabalhistas. O suicídio de Vargas em 1954 foi precedido pela primeira onda de greves de massa; a deposição de João Goulart pelos militares em 1964 foi precedida pela segunda onda de greves de massas e por intensos conflitos no campo; a vitória eleitoral de Collor (que era mais o anti-Lula do que o candidato ideal das classes dominantes) em 1989 e sua posterior deposição por meio de processo de impeachment em 1992 foram atravessadas por uma das maiores mobilizações grevistas da história brasileira; o impeachment de Dilma foi precedido por um crescimento surpreendente do número de greves a partir de 2012. O alinhamento político das frações superiores da burguesia contra o movimento popular e sindical em todas essas conjunturas indica um padrão de comportamento das classes dominantes, isto é, um comportamento tendencialmente conservador para a resolução de crises políticas ou situações de forte instabilidade política. O que parece variar são os métodos adotados: mais ou menos violentos, mas quase todos voltados para impugnar o processo democrático.

Nas crises do capitalismo neoliberal brasileiro, o alinhamento da grande burguesia interna com o imperialismo para derrotar Lula a qualquer custo em 1989 foi profundamente influenciado pela ascensão das greves e pela proposta defendida pelo candidato de PT de instituir uma espécie de Estado de bem-estar social no Brasil, o que contrariava a onda neoliberal que atingia a América Latina naquele momento. Na eleição de Lula de 2003, o movimento popular e sindical estava em grande medida domesticado. Com exceção do MST que fazia um enfrentamento político orientado por uma linha política antiliberal e vinha realizando várias ocupações de terra, o movimento sindical caminhava na direção do sindicalismo cidadão, que só critica os efeitos do neoliberalismo (desemprego, pobreza, redução dos salários, etc.) e não propriamente o conteúdo desta política. Além disso, o movimento grevista vinha perdendo fôlego desde 1997. Numa conjuntura de relativa calmaria do movimento sindical e de desgaste do neoliberalismo, a grande burguesia interna soube aproveitar-se da conjuntura para fazer valer seus interesses e ganhar espaços nas zonas de menor tensão com o imperialismo. É nesse momento que a grande burguesia conseguiu direcionar ideologicamente setores importantes do movimento popular e sindical e também dos trabalhadores a uma plataforma política que não apontava para a ruptura, mas para a 
reforma no capitalismo neoliberal. No final da década de 2000, esse movimento reformista começou a entrar em crise e um dos fatores principais para a emergência desta crise foi justamente a eclosão de uma nova grande onda de greves e protestos sociais, o que indicava certo desgaste desse processo reformista. A partir de 2013, novos (ou velhos?) personagens entram em cena e passam a ocupar as ruas exigindo o fim da corrupção, especialmente no momento posterior à vitoriosa luta progressista da juventude contra o aumento das tarifas de transporte coletivo. Nos anos seguintes, a instabilidade política foi ganhando as ruas. Contando com forte apoio da mídia conservadora, um massivo movimento de classe média tomou as ruas contra a corrupção, o petismo e a presidente Dilma. A grande burguesia interna desembarcou deste governo e passou a participar ativamente dessas mobilizações até vir a aderir ao golpe de Estado.

Se os interesses do imperialismo quase sempre se chocaram com os interesses dos trabalhadores, o que os levou a apoiar golpes na América Latina nas situações mais críticas, ou seja, se o imperialismo reivindica fundamentalmente uma política antipopular para os países dependentes, isso não pode nos levar a concluir que a grande burguesia brasileira e outras burguesias latino-americanas são tendencialmente progressistas. Nada disso. O processo histórico brasileiro denota que as concessões materiais aos trabalhadores foram muitas vezes feitas graças à pressão da luta dos próprios trabalhadores ou de ações antecipadas da burocracia de Estado, como parece ser o exemplo dos programas sociais dos governos petistas. Num quadro de crescente internacionalização do capital, que afeta os setores mais concentrados, é difícil esperar da grande burguesia interna qualquer tipo de posicionamento progressista de longo prazo, que aponte para a ampliação do mercado de massas e para a defesa de um verdadeiro movimento nacionalista anti-imperialista. É mais fácil esperar desta grande burguesia interna ações de apoio ao imperialismo, especialmente nos momentos em que a crise econômica se fizer presente e o movimento popular e sindical também.

Assim como o movimento do pêndulo nunca encosta no chão, na base, o mesmo tem ocorrido com as oscilações políticas da grande burguesia interna que, mesmo nas situações de relativo crescimento econômico, não se mostra interessada em realizar amplas concessões materiais aos trabalhadores. Até quando essa situação se manterá? Não sabemos. O certo é que a solução de parar o pêndulo no meio, proposta por Diamand, está muito distante de ser uma alternativa ao liberalismo econômico e à corrente expansionista. Um híbrido jamais é uma alternativa efetiva às partes que o compõem. O mesmo raciocínio poderia ser feito para o que representa o meio entre o imperialismo e a grande burguesia interna. Certamente, os 
trabalhadores não figurarão aí. Ao que parece, o pêndulo só deixará de oscilar quando for destruído pelos próprios trabalhadores. 